\title{
Ecological Aspects of The Vectorial Control of Chagas' Disease in Brazil
}

\author{
Aspectos Ecológicos do Controle de Vetores para Doença de Chagas \\ no Brasil
}

\author{
João Carlos P. Dias ${ }^{1}$
}

\begin{abstract}
DIAS, F. C. P. Ecological Aspects of The Vectorial Control of Chagas'Disease in Brazil. Cad. Saúde Públ., Rio de Faneiro, 10 (supplement 2): 352-358, 1994.
\end{abstract}

The feasibility and most important ecological aspects of vectorial Chagas' disease control are discussed. The spread and maintenance of this disease involve multiple ecological and sociopolitical factors that must be taken into account when control programs are planned, executed and evaluated. In spite of its complexity, Chagas disease can be controlled using methods that target specific mechanisms of transmission, the most important being vectorial and transfusional.

Major ecological problems in Chagas' disease control do not exist, even in the case of the chemical control of triatomine vectors. The main challenges for the Brazilian Control Program at this moment are: its maintenance as a political priority; the threat of peridomestic vectors; and the consolidation of permanent horizontal and participative epidemiological surveillance systems against the vector.
Key words: Chagas'Disease; Trypanosoma cruzi infection; Vector Control; Triatomine Vectors; Ecology Vectors

\section{INTRODUCTION}

Chagas' disease (CD) was described by Dr. Carlos Chagas in Minas Gerais, Brazil, in 1909. It is an endemic anthropozoonotic disease affecting 15 million individuals in Latin America, with at least 90 million people at risk (WHO, 1991). CD is a vector-borne disease whose etiologic agent, Trypanosoma (Schizotrypanum) cruzi is a flagellate protozoan that circulates in the sylvatic cycle and has more recently become adapted to a domestic cycle, involving human beings. More than 150 wild and domestic small mammals serve as reservoir hosts, including marsupials, wild and domestic rodents, rabbits, raccoons, dogs, cats and bats. In the

${ }^{1}$ Centro de Pesquisas René Rachou da Fundação Oswaldo Cruz. Avenida Augusto de Lima, 1715, Caixa Postal 1743, Belo Horizonte, MG, 30190-002, Brasil. domestic cycle the most important reservoir has been man himself (Barretto, 1979; Dias, 1987).

Several genera of triatomines (Hemiptera, Reduviidae, Triatominae) serve as CD vectors. They are strictly haematophagous insects, widespread in several kinds of natural and artificial ecotopes of America, but also in other continents where CD does not exist, such as Asia, Europe and Africa (Sherlock, 1979). More than $80 \%$ of human CD is attributable to vector transmission, but transmission by blood transfusion is also becoming important in endemic (and even in nonendemic) countries (WHO, 1991).

Congenital transmission of the parasite can also be significant in certain areas, with a risk of infection of $1 \%$ or more in babies born from infected mothers (Dias, 1987). In the sylvatic cycle, oral transmission seems to be very common among small mammals that eat both infected hosts and triatomine bugs (Barretto, 1979; Zeledon, 1974). 
Human CD begins with an apparent or inapparent acute phase that is more severe (even lethal) in young children. The chronic phase is the most important from the epidemiological point of view, when cardiac and/or digestive clinical forms can affect up to $30 \%$ of infected individuals in endemic areas (Marsden, 1983).

This article revises ecological aspects of $\mathrm{CD}$ and its control. Since it is assumed that $\mathrm{CD}$ is a real priority for Brazil and for Latin America, its control must be carried out with rationality and ecological responsibility (Dias, 1987).

\section{ECOLOGICALAND SOCIALASPECTS OF CHAGAS' DISEASE}

Some 43 species of triatomines have been found in Brazil, most of them associated with sylvatic ecotopes such as palms, opossum and rodent lodges, bird nests, armadillo burrows, etc. The most important vectors of human CD are those which are able to enter and colonize houses, the so-called "domestic" triatomines. Interaction between human beings and triatomines occurs basically inside poor houses, where microclimatic conditions offer exceptionally favorable conditions for bug colonization. According to Forattini (1980), the "domicialiarity" of triatomines happens through an opportunistic mechanism that involves shelter and food availability factors. Once established, domiciliarity favors species survival, thus increasing their success in synanthropic specialization. Spread of human CD usually occurs depending on human migration and active or passive triatomine transportation (Dias, 1988). Triatoma infestans is the most domesticated of the major species, being detected throughout the so-called chaco-cerrado-caatinga complex, an open space extending from the northeastern part of Chile and Argentina to Northeastern Brazil. T. infestans was probably spread from the Cochabamba Valley, in Bolivia, and is considered as an introduced species in Chile, Argentina, Uruguay, Paraguay and Brazil, where it remains restricted to domestic and peridomestic habitats (Bucher \& Schofield, 1981). Other important vectors of human CD are Triatoma sordida (Argentina, Bolivia and the dry "cerrado" in Brazil), Panstrongylus megistus (humid Atlantic forest, Brazil), Triatoma brasiliensis (dry regions of Northeastern Brazil), Rhodnius prolixus (from Colombia to Mexico), and Triatoma dimidiata (also in the North of South America and Central America). Unlike T. infestans, these species are not restricted to domestic environments and can frequently be found in sylvatic ecotopes near human dwellings. A series of other sylvatic triatomines such as $R$. neglectus and $R$. nasutus, living in palm trees, or T. rubrovaria, that can be found in rock piles, or P. geniculatus, generally associated with armadillos, can sporadically invade houses and even produce small colonies (Barretto, 1979). The pattern of rural settlement and human migration, together with ecological changes and "anthropic" effects on the environment, appear to have favored the bugs, allowing them to colonize poor rural dwellings over a wide area of three million square kilometers in Brazil (Dias, 1987; Schofield, 1980; Sherlock, 1979). In recent decades a clear tendency towards CD "urbanization" has been observed in several parts of the endemic area, due to rural-urban migration. Thousands of infected individuals are living today in the metropolitan areas of São Paulo, Caracas, Buenos Aires, Santiago, and even New York or Los Angeles, so increasing the risk of $T$. cruzi transfusional transmission. Passive transportation of triatomines is very common, but the colonization of urban spaces appears not to be as easy as in rural areas (Marsden, 1983). Nevertheless, significant colonies of $T$. dimidiata, T. sordida and T. infestans can be detected respectively in Guayaquil and Tegucigalpa, in Santa Cruz and in Cochabamba, showing that urban adaptation is possible (Dias, 1988).

In conclusion, ecological factors such as altitude, temperature and humidity are very important in the context of $\mathrm{CD}$, but social elements (poverty, development) and the changes produced by human beings in the environment ("anthropic actions") are also major factors and determinants of human CD. 


\section{THECONTROLOFCHAGAS' DISEASE}

Since mass treatment or vaccination against $T$. cruzi is not feasible due to the lack of suitable drugs or vaccines, the best approach to CD control concerns transmission mechanisms. Several field observations and even some mathematical models show that social and economic development of endemic areas is sufficient to achieve CD control, mainly by eliminating or reducing man-vector contact (Dias, 1987; WHO, 1980).

Nevertheless, unlike many other endemic parasitic diseases, CD can also be controlled by direct and specific interventions, such as by eliminating domestic vector populations and selecting blood donors.

Since more than $80 \%$ of CD is attributable to transmission by the vectorial route, control of domestic triatomines is the principal target of control programs, mainly using insecticides and housing improvement. The general results of national programs carried out in Brazil, Venezuela, Uruguay and Argentina can be considered very good in those areas where the actions were performed with a minimum degree of continuity. Domestic bug populations were drastically reduced in all areas where control measures were carried out, and remarkable decrease of CD incidence among the population was observed (Dias, 1987; Tonn, 1988). For the most part, chemical spraying is considered a short-term approach, while housing improvement is a long-term approach to CD control (Dias \& Borges Dias, 1982; WHO, 1980; Tonn, 1988). These strategies are clearly complementary and must be encouraged in endemic areas while taking account of local conditions. The specific control of sylvatic CD does not make sense, nor does the control of vertebrate reservoirs. Eradication of strictly domestic species such as $T$. infestans is an attainable goal in some regions, as observed in almost $85 \%$ of the Brazilian area where this bug was present at the beginning of the program (Dias, 1987). In the case of other species that live both in houses and in sylvatic ecotopes, the programs can only control populations in the domestic environment (Forattini et al., 1979; Marsden, 1983).
In general, control programs start with an "attack" phase involving massive insecticide spraying, followed by a consolidation phase (selective spraying of infested houses) and then by a surveillance phase. Housing improvement can be carried out at any point in the program but if it is performed alone, the results are poorer and slower than those obtained using insecticides (WHO, 1980). From an economic and social point of view, it would be interesting to promote $\mathrm{CD}$ control by means of housing improvement, since the programs could be supported multisectorally (i.e., not only by the Ministry of Health), and the results would bring much greater benefit to the population than bug control alone (Bos, 1988). Nevertheless, the only national program based on housing improvement was in Venezuela two decades ago (Tonn, 1988). The investment seems to be very high for poor endemic areas, and the governments of the affected countries do not give priority to poor rural populations (Dias, 1988).

In practice, conventional application of residual insecticides is the most practicable approach to $\mathrm{CD}$ control. The basis of this work was established by Emmanuel Dias in Brazil, employing BHC in systematic campaigns against domestic triatomines (Dias, 1957). Insecticide utilization must be rationalized in order for the minimum effective dosage to be used, thus avoiding environmental damage and side effects on householders and sprayers. Taking into account the habits and long life cycle of the triatomines, the best insecticides are those with a prolonged residual effect and the ability to work through contact with the insect (Dias, 1945; Zerba, 1988). Modern programs are replacing the old organochlorine and organophosphate products with modern synthetic pyrethroids such as deltamethrin, cypermethrin, cyfluthrine and lambdacyhalothrine, with the advantage of longer residual activity and much less damage to the environment (Dias, 1987).

The rationale of these programs is to completely eliminate domestic colonies of triatomines and to maintain a permanent surveillance against new colonization. The results in Brazil are very good with $T$. 
infestans, but in some areas species such as $T$. brasiliensis, T. sordida and $T$.

pseudomaculata continue to present obstacles to control, since they retain sylvatic ecotopes and can readily invade sprayed houses (chiefly via the peridomestic area) when residual insecticide activity declines (Bos, 1988; Dias, 1987; Marsden, 1983).

The challenge now is to establish an effective and permanent vigilance phase by mobilizing local communities to participate in vector surveillance, mainly in the peridomestic environment, where insecticides usually do not work as well. From the pragmatic point of view, it is almost impossible to maintain permanent vertical programs involving periodic revision of thousands of houses, in poor, sparsely populated isolated and endemic regions. Local surveillance systems can be much more effective in the detection of residual triatomine foci, as a result of the motivation and participation of the householders, followed by immediate spraying of infested houses (Dias, 1987; Tonn, 1988). For peridomestic situations, possible alternatives for vector control are the biological approach and environment management. Research interest remains high for biocontrol against triatomine bugs, and the most promising results seem to be with the fungi Metarrizium anisopliae and Beauveria bassiana. Experimental work has shown that fungal spores sprayed on the surroundings can maintain successful control of different triatomine species (Marsden, 1983; Tonn, 1988). Environmental management seems to be the correct approach for peridomestic triatomine control, particularly if the population is involved. According to Bos (1988), the methods should first of all be aimed at reducing suitable habitats for the bugs, including outhouses, either for animals or for storage of agricultural products, and specific types of vegetation. For Brazilian conditions, according to millions of data units produced yearly by the Superintendência de Campanhas de Saúde Pública (Sucam), the main target in peridomestic areas should be the very primitive chicken-houses, piles of firewood, tiles and bricks, and goat or sheep corrals, where small colonies of $T$. sordida, $P$. megistus, T. pseudomaculata, T. brasiliensis, Rhodnius neglectus, etc., can be found.

The question about insecticide resistance seems not to be very important in CD control. In general, triatomine bugs are very susceptible to the modern pyrethroids, with no resistance having been detected for the main species in a number of countries (Dias, 1987; Tonn, 1988; Zerba, 1988). In Venezuela, many years ago, $R$. prolixus strains in Portuguesa state revealed resistance against Dieldrin and other organochlorine products, but the problem was solved with propoxur (Tonn, 1988).

On the other hand, the ecological impact of insecticide programs against $C D$ vectors can be minimized if some well-established operational rules are followed. Human or environmental accidents have not been observed during the current Brazilian National CD Program, which sprayed about 500,000 houses per year over the last six years, even after the introduction of synthetic pyrethroids (Dias, 1987).

\section{ECOLOGICAL ASPECTS OF CD CONTROL}

There is no doubt among specialists that CD control constitutes a real priority throughout Latin America, since the social and economic damages resulting from this protozoal infection are very high in the continent. On the other hand, in spite of the lack of social development of the populations exposed to the CD vectors, several modifications in rural areas have taken place in endemic countries. Most of them are producing changes in the ecology and distribution of the disease, resulting chiefly from the effects of humans on the environment, such as human migration, agricultural projects, the mechanization of agriculture and the effect of long-term spraying of pesticides on crops, the introduction of electricity in rural areas, the construction of large dams, and the reforestation of extensive areas with foreign species (Pinus, Eucalyptus), etc. (Dias, 1988; Forattini, 1980). As a natural consequence of 
these factors, the epidemiology of CD is changing throughout the continent, and it is even possible that new endemic areas could arise from human intervention in virgin areas such as the Amazon Region. Some predictable situations can be observed under different ecological and socioeconomic conditions (Dias, 1988):

a. The maintenance of traditional CD cycles in poor untreated and isolated areas, with low rates of social and environmental changes and no control programs;

b. A progressive jeopardizing of the sylvatic cycle in all areas subjected to intensive anthropic action. For instance, there is a progressive decrease in $T$. sordida natural populations in the dry "cerrado" areas of Goiás or Bahia state, in Brazil, where intensive and extensive soya bean cultivation is being carried out. In such situations the natural flora is completely disturbed and submitted to permanent pesticide pressure, not only killing triatomines themselves but also destroying their natural ecotopes and driving away vertebrate food sources;

c. The progressive substitution, at the domestic level, of former principal vectors by "secondary" species, as a consequence of systematic insecticide spraying producing ecological lacunae. This is particularly evident in areas where T. infestans is being eradicated and house invasion by $P$. megistus or $T$. sordida tends to occur (Barretto, 1979, Dias, 1988, Forattini et al., 1979);

d. The imbalance between triatomines and their natural enemies, also as a consequence of insecticide campaigns and/or other anthropic actions over the ambient. Here, two additional points should be emphasized:

1. Rational insecticide campaigns, performed at the household level, do not produce negative ecological impact;

2. It makes no sense to spray chemical products in sylvatic ecotopes in order to control triatomines; e. The increasing importance of the peridomestic environment that tends to concentrate triatomines and reservoirs, since the artificial and sylvatic ecotopes are suffering intensive human interventions. In this case, an associated tendency is the appearance of less restricted peridomestic cycles of $T$. cruzi than are usually observed, involving triatomines and some domestic and/or synanthropic mammals such as goats, rodents and marsupials (Barretto, 1979; Dias, 1988; Forattini et al., 1979; Zeledon, 1974);

f. The disruption of barriers for some triatomines. For instance, $R$. prolixus is being detected in southern regions of Brazil, while T. infestans can now be captured at altitudes above 3,000 meters (Bolivian Altiplan) or near the seashore (in Rio de Janeiro, Brazil, some years ago);

g. The concentration of vectors and human reservoirs in preserved sylvatic microhabitats, surrounded by human intervention. A good example of this situation is described by Forattini (1980) in São Paulo state, Brazil, where extensive sugar-cane cultivation leaves small preserved furrows in which $P$. megistus is associated with vertebrate hosts heavily infected with T. cruzi.

\section{FINAL REMARKS AND MAIN CONCLUSIONS}

Concrete possibilities for controlling human $\mathrm{CD}$ are available at present, but only four or five of the 18 Latin American endemic countries have established control programs (WHO, 1991). As pointed out by Tonn (1980), "in theory there should be few limits to the technical possibilities of the science of vector control to control Chagas' disease. In reality, besides the fact that development of improved technology exceeds its application, the government and vector control specialists are faced with the constraints of poverty, population increase and chaotic economical growth on chemical control or housing improvement. Basically the 
achievements of better environmental

sanitation and housing conditions,

components of the public health revolution, have not reached many people in the developing world". With such a perspective, the main problem for CD control is really to strengthen the political will to initiate and to maintain a minimum degree of continuity and technical conditions in the programs. On the other hand, it must be emphasized that CD control is something more than mere chemical spraying, that it also involves environmental management, housing improvements, health education, and community participation (Dias, 1987; WHO, 1991). It is becoming increasingly clear that isolated measures or programs do not work very well. In this regard, the initiative by countries from the Latin American Southern Cone to give priority to CD control by means of an integrated international effort must be considered a historical decision $(\mathrm{PAHO}$, 1993). It is apparently no coincidence that the whole world is discussing Ecology, Ethics, and Health as a right for all. In such a context, a unique opportunity exists to bring together scientists, public health professionals, community leaders, and politicians to discuss not only technical approaches to CD control, but also the ecological and even the political and social issues involved in it. As mentioned above, this control depends basically on political decisions by endemic countries, a fact that could also mean a very special kind of development (Dias, 1988).

\section{CONCLUSIONS}

a. Chagas' disease is not an isolated problem in Latin America, but is strongly associated with the social, political and ecological problems of the affected countries;

b. The control of Chagas' disease is feasible from the technical point of view, but to be consolidated it requires political decisions and integrated efforts among public health professionals, the scientific community, the government, and the general population; c. At the technical level, the principal challenges in Brazil are now the management of vector species in peridomestic areas and the maintenance of a continuous and horizontal program of epidemiological surveillance;

d. Since the original sylvatic cycle of $T$. cruzi must be preserved from the ecological point of view, continuing attention must be paid to ecological and social changes in endemic areas, in order to detect new epidemiological situations, including the possible establishment of a domestic cycle in the Amazon Region and other new agricultural frontiers. It is also the case of the spread of the disease to urban centers and non-endemic areas via migration, blood transfusion, and organ transplantation;

e. There are no important ecological constraints on current Chagas' disease control programs, since they are performed rationally;

f. Additional research is required to improve the current control methods and strategies and to look for alternative approaches to them in new epidemiological situations.

\section{ACKNOWLEDGMENT}

The author is indebted to Prof. Philip D. Marsden for revision of the manuscript.

\section{RESUMO}

\section{DIAS, J. C. P. Aspectos Ecológicos do} Controle de Vetores para Doença de Chagas no Brasil. Cad. Saúde Públ., Rio de Janeiro, 10 (suplemento 2): 352-358, 1994.

A importância da doença de Chagas e de seu controle é assinalada para o Brasil e demais países endêmicos da América Latina, enfatizando-se os aspectos ecológicos envolvidos. Os principais insumos e 
estratégias de combate à doença humana já existem e estão disponíveis, devendo-se priorizar o controle dos vetores domiciliados e das transfusões de sangue. Os programas de controle devem levar em conta os elementos ecológicos e sociais pertinentes, inclusive para se prevenir novas situações epidemiológicas no futuro. Não se assinalam problemas ecológicos de importância quando os programas de controle são planejados e executados com racionalidade. Os maiores desafios ao programa brasileiro, são hoje, a manutenção de sua continuidade a nível nacional, o controle de vetores secundários no peridomicílio e a consolidação de uma vigilância epidemiológica horizontalizada e participativa.

Palavras-Chave: Doença de Chagas; Trypanosoma cruzi; Controle de Vetores; Triatomíneos; Ecologia de Vetores

\section{REFERENCES}

BARRETTO, M. P., 1979. Epidemiologia. In: Trypanosoma cruzi e Doença de Chagas (Z. Brener \& Z. Andrade, eds.), pp. 89-151, Rio de Janeiro: Guanabara Koogan.

BOS, R., 1988. The importance of peridomestic environmental management for the control of the vectors of Chagas' Disease. Revista Argentina de Microbiologia, 20 (supl.): 58-62.

BUCHER, E. H. \& SCHOFIELD, C. J., 1981. Economic assault on Chagas' disease. New Scientist, 92: 321-324.

DIAS, E., 1945. Um Ensaio de Profilaxia de Moléstia de Chagas. Rio de Janeiro: Imprensa Oficial. , 1957. Profilaxia da doença de Chagas. O Hospital, 51: 285-289.

DIAS, J. C. P., 1987. Control of Chagas' disease in Brazil. Parasitology Today, 3: 336-341. , 1988. Rural resource development and its potential to introduce domestic vectors into new epidemiological situation. Revista Argentina de Microbiologia, 20 (supl.): 81-85.

DIAS, J. C. P. \& BORGES DIAS, R., 1982. Las viviendas y la lucha contra los vectores de la enfermedad de Chagas en el hombre, en el Estado de Minas Gerais, Brasil. Boletin de la Oficina Sanitaria Panamericana, 93: 453-467.
FORATTINI, O. P., 1980. Biogeografia, origem e distribuição de triatomíneos no Brasil. Revista de Saúde Pública, 14: 265-299.

FORATTINI, O. P.; FERREIRA, O.; ROCHA E SILVA, E. O. \& RABELLO, E. X., 1979. Aspectos ecológicos da tripanossomíase americana. XIV: Persistência e potencial de domiciliação de populações triatomínicas silvestres em região de intensa atividade agropecuária. Revista de Saúde Pública, 13: 123-146.

MARSDEN, P. D., 1983. The transmission of Trypanosoma cruzi infection to man and its control. In: Human Ecology and Infectious Diseases (N. A. Croll \& J. H. Cross, eds.), pp. 253-281, London: Academic Press.

PAHO (Pan-American Health Organization), 1993. Iniciativa del Cono Sur para la eliminación de la transmisión vectorial y la interrupción de la transmisión transfusional del Trypanosoma cruzi. Intern Document, PNSP/92, Washington, DC: PAHO. (Mimeo.)

SHERLOCK, I. A., 1979. Vetores. In: Trypanosoma cruzi e Doença de Chagas (Z. Brener \& Z. Andrade, eds.), pp. 42-88, Rio de Janeiro: Guanabara Koogan.

SCHOFIELD, C. J., 1980. Density regulation of domestic population of Triatoma infestans in Brazil. Transactions of the Royal Society of Tropical Medicine and Hygiene, 6: 761-769.

TONN, R. B., 1988. Review of recent publications on the ecology, biology and control of vectors of Chagas' disease. Revista Argentina de Microbiologia, 2 (supl.): 04-24.

WHO (World Health Organization), 1980. Description of the Final Simulation Model, Including a List of the Computer Program and the Data Files. Workshop about mathematical model in the control of Chagas' disease. (J. Rabinovich, Coord.), Caracas, IVIC. (Mimeo.) , 1991. Control of Chagas' Disease. Geneva: WHO. (Technical Reports Series, 811)

ZELEDON, R., 1974. Epidemiology, modes of transmission and reservoir hosts of Chagas' disease. Ciba Foundation Symposium, 20: 51-77.

ZERBA, E. N., 1988. Conventional insecticides: mechanisms of action, resistance and byoassay in Chagas' disease vectors. Revista Argentina de Microbiologia, 20 (supl.) 32-37. 